\title{
Scale up use of family planning services to prevent maternal transmission of HIV among discordant couples: a cross-sectional study within a resource-limited setting
}

\author{
This article was published in the following Dove Press journal: \\ Patient Preference and Adherence \\ 3 October 2016 \\ Number of times this article has been viewed
}

\author{
Martin Kuete ${ }^{1,2}$ \\ HongFang Yuan' \\ Aude Laure Tchoua \\ Kemayou ${ }^{2}$ \\ Emmanuel Ancel Songo ${ }^{2}$ \\ Fan Yang' \\ XiuLan $\mathrm{Ma}^{\prime}$ \\ ChengLiang Xiong' \\ HuiPing Zhang' \\ 'Obstetrics and Gynecology, \\ Reproductive Center, Family Planning \\ and Research Institute, Tongji Medical \\ College, Huazhong University of \\ Science and Technology, Wuhan, \\ Hubei, People's Republic of China; \\ ${ }^{2}$ Main Maternity of Obstetrics and \\ Gynecology, Yaounde Central Hospital, \\ Faculty of Medicine and Biomedical \\ Sciences, Yaounde, Cameroon
}

Correspondence: HuiPing Zhang Family Planning and Research Institute, Tongji Medical College, Huazhong University of Science and Technology, 13 Hangkong Road, Wuhan 430030, Hubei, People's Republic of China

Tel +86 I30 35I3 3247

Fax +86278369 265।

Email familyplanning2013@163.com
Background: Integration of family planning services (FPS) into human immunodeficiency virus (HIV) care for HIV-infected women is an important aspect of the global prevention of mother-to-child transmission (PMTCT) strategy. We assessed the integration of FPS into routine care of HIV-infected mothers by evaluating the uptake and barriers of contraception and PMTCT services.

Methods: We conducted an interventional study using the interrupted time series approach in the health care facilities located in Yaounde, Cameroon. First, structured questionnaires related to family planning use, PMTCT services use, and infection risk of the sexual partner were administered to the first trimester pregnant women who were HIV infected and living with uninfected partners. Second, 2 weeks before the delivery date, the women were interviewed according to the prior counseling interventions received, in order to assess their behavior on FPS, antiretroviral therapy (ART) use, delivery option, and infant nourishment to be adopted. $P$-values below 0.05 were considered statistically significant in the statistical analyses.

Results: Of 94 HIV-infected women, $69 \%$ were stable couples. Only 13\% of women had attended FPS before conception. Although the vast majority were knowledgeable about modern and traditional contraception methods, only $19 \%$ had experienced effective contraceptive methods. However, $66 \%$ preferred condom use, $45 \%$ having three children still expressed a desire to conceive, while $44 \%$ reported abortions, $65 \%$ had tried to avoid the current pregnancy, and $12 \%$ of women were ART naïve. Several predictors such as education, abortion rate, unplanned pregnancies, and partners' decision were associated with the nonuse of effective contraceptive methods. Moreover, barriers including sex inequity, lack of partner support, ART shortages, and lack of HIV viral load monitoring were prevalent among the participants $(P=0.001)$. However FPS use, ART compliance, and safe options to PMTCT significantly increased after the educational counseling interventions $(P=0.001)$.

Conclusion: Scaling up the FPS by incorporating routine PMTCT services into reproductive health care should contribute to preventing both horizontal and vertical transmission of HIV.

Keywords: contraception, HIV infected women, transmission, interventions, education

\section{Introduction}

In the year 2000, the world leaders pledged to reduce child mortality by three fourths, improve maternal health, and combat human immunodeficiency virus/acquired immunodeficiency syndrome (HIV/AIDS) by 2015, as outlined in the Millennium Development Goals 4, 5, and 6. ${ }^{1}$ Therefore, 2015 was expected to be the turning point for 
health decision makers to rethink and define new perspectives for maternal and child health in poor settings dominated by HIV/AIDS and poverty. Sub-Saharan Africa (SSA) is especially deficient in terms of reproductive health services to meet the Millennium Development Goals for maternal and child health. More than 287,000 women and girls still die of pregnancy- and delivery-related complications every year. Also, presently, >222 million women in developing countries want to avoid or delay pregnancies; unfortunately, they do not have access to the family planning services (FPS), especially the modern contraceptives. ${ }^{2,3}$

Despite several initiatives taken to stop HIV infections worldwide, $>3.2$ million children under 15 years of age are infected, with $91 \%$ of this population living in SSA. ${ }^{4}$ Even though the number of newly infected children in Africa fell from 350,000 in 2009 to 199,000 in 2013, the rate of motherto-child transmission (MTCT) remains very critical. ${ }^{3,5}$ Most people living with HIV are in ongoing sexual relationship with HIV-negative partners, a fact that significantly contributes to 2.1 million new infections globally.,6 It has been documented that the transmission of HIV from an infected to an uninfected partner accounts for one-third of all new infections. Many couples in Africa are unaware of their HIV-discordant status, and the annual risk of infection for a negative partner is about $10 \%-95 \%{ }^{{ }^{7-12}}$ Studies have shown that the majority of HIV-infected women engaged with uninfected partners make an average contribution of $30.4 \%$ in stable couples (one partner testing HIV seropositive, while the other testing HIV seronegative) and up to $40.2 \%$ in unstable couples. ${ }^{11-14}$ Furthermore, an estimated 1.5 million infected women have given birth and many do not have access to services that prevent mother-to-child transmission (PMTCT) of HIV. Also, $>91 \%$ of new infections among children occur by vertical transmission. ${ }^{15}$ This implies that almost all new HIV transmissions among children occur during pregnancy, labor, delivery, and breastfeeding. The transmission rate can range from $15 \%$ to $45 \%$, while many studies have shown that effective interventions including use of family planning (FP) can reduce MTCT below 2\%. ${ }^{3,4,7,16-19}$ Overall, PMTCT and FPS are still underused by HIV-infected women in SSA. ${ }^{20-24}$

In Cameroon, an estimated 660,000 people were living with HIV in 2014, with about 350,000 of this number being women above 15 years of age. The prevalence rate among adults aged $15-49$ years was $4.8 \% .{ }^{25}$ Recently, Billong et al found that the prevalence of HIV among pregnant women has remained steady at $7.8 \%$ in the country during the last 3 years. ${ }^{26}$ For several decades, the total fertility rate has remained high due to the limited use $(23.40 \%)$ of FPS. ${ }^{27}$
Besides policies and promising strategies currently being implemented to stop new HIV infections, a large part of infections among children stem from contextual unmet needs and poorly designed interventions. ${ }^{28-31}$ To date, a large majority of HIV-infected women in relationship with uninfected partners do not have access to PMTCT and supportive services for reproductive health. Consequently, the HIV-negative partners and children are still being infected. To control the HIV epidemic in resource-limited settings, innovative approaches are needed and FPS use is indicated in order to prevent new infections.

In this study, we assessed integration of FPS into routine care of HIV-infected mothers by evaluating the uptake and barriers of contraception and PMTCT services.

\section{Materials and methods}

\section{Study design, settings, and participants}

We performed a cross-sectional survey at the Yaounde Central Hospital ( $\mathrm{YCH}$ ) located in the center of Cameroon. Self-administered questionnaires were used and interviews conducted during the pretesting and recruitment of participants (Figure 1). Questionnaire design was in accordance with the previous recommendations, validated studies, and guidelines. ${ }^{6,12,15}$ This survey was conducted between February and December 2014. To be eligible for the overall study and analysis, participants had to satisfy the following criteria: 1) they had to be HIV (+) women in their first trimester of pregnancy; 2) they had to provide accurate personal and partner medical histories on HIV status and FPS use; 3) they should have attended at least one session of FP education; and 4) they should have given birth at the main maternity of $\mathrm{YCH}$. Furthermore, medical record review confirming the pregnancy and HIV status was conducted to confirm the characteristics of all participants. Completed copies of the questionnaire were serially numbered for control and recall purposes.

\section{Variables}

Sociodemographic information included: age, marital status, religion, education, occupation, residency, partner's education and profession, and participants' and partners' HIV status.

Reproductive health and FP services included: parity, interpregnancy spacing, abortion/miscarriages, planned and unplanned pregnancy, contraception use, and discussion and decision making for contraception of couples.

Information collected on HIV/AIDS, PMTCT, and risk of uninfected partner included: HIV disclosure, condom 


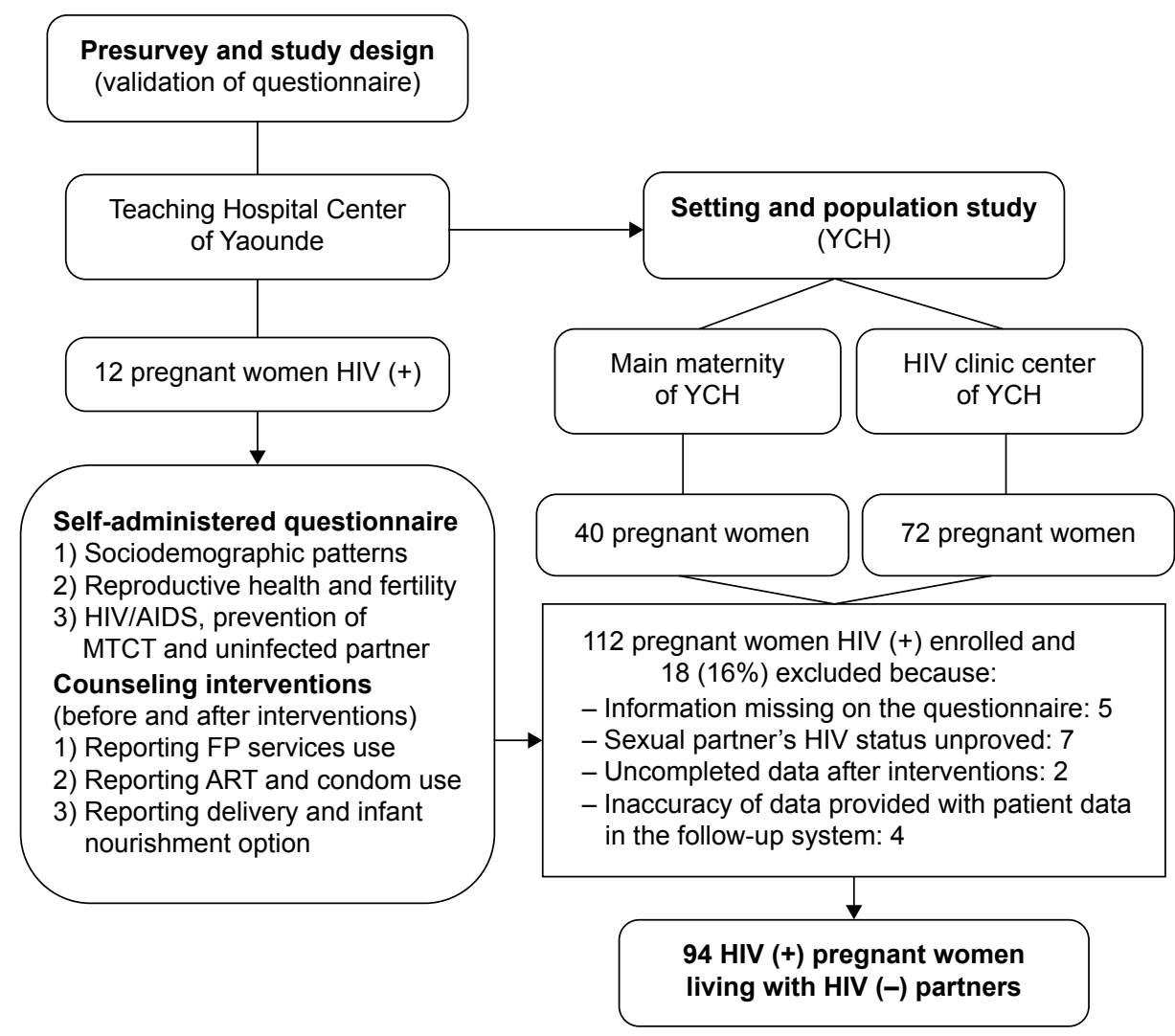

Figure I Study design, setting, and participants' selection.

Abbreviations: AIDS, acquired immunodeficiency syndrome; ART, antiretroviral therapy; FP, family planning; HIV, human immunodeficiency virus; MTCT, mother-to-child transmission; YCH, Yaounde Central Hospital.

use, antiretroviral therapy (ART) accessibility, intake, and adherence, newborn breastfeeding option, participants' selftasks, and inputs for PMTCT.

Participants' behavior to PMTCT before (during the first trimester of pregnancy) and after the counseling interventions at 2 weeks prior to delivery was assessed with regard to the following: FPS, ART, delivery option, and infant nourishment.

\section{Measurements}

The participants provided consistent answers to 12 questionnaire items, by which reproductive health and FP use were assessed. They were asked to report within a range of contraceptive methods the prior contraception before pregnancy, nature of the current pregnancy (intended or unwanted pregnancy), perception of their partner on FP use, decision making for FP in their household, report any case(s) of abortion/miscarriage or stillbirth over the last 12 months, reasons for the "nonuse" of effective contraception methods, and the couple's plans regarding future pregnancies and their expected number of children. The majority of answers were dichotomous "yes" or "no".
To assess HIV/AIDS, PMTCT, and the risk for uninfected partner, the respondents were asked to report their partner's HIV status and the latest report of HIV testing (confirmed by the HIV testing unit), HIV test disclosure among couples, condom use to control infection, and circumstances of HIV transmission in both horizontal and MTCT by answering "yes" or "no" to 13 questionnaire items. Also, ART use and accessibility were assessed with the options "every time", "sometime", "hardly", and "never have been on ART" to describe the frequency of accessibility.

To evaluate the behavior of participants regarding PMTCT, we assessed their awareness and attitude before and after counseling interventions prior to delivery (about 6 months interval) on FPS, condom use, ART taken, delivery option chosen, and infant feeding option chosen.

\section{Data collection procedures}

Structured questionnaires were administered at the time of enrollment and an interview guide was used during interviews that were conducted during counseling sessions about 2 weeks prior to childbirth. Before pretesting, all members of the study team (two midwives, one nurse, and 
one medical doctor) were trained on how to use the two data collection instruments. This was to ensure that they all understood and were familiar with these instruments. Responses from 12 participants who participated in the presurvey confirmed the accuracy and validity of the survey instruments. During the counseling intervention sessions, figures and illustrations from the Centers for Disease Control and Prevention were used to optimize the education of the participants on the effectiveness of contraception methods. ${ }^{32}$ The survey was conducted by the principal investigator alongside three trained regular clinicians (midwives and nurse) with prior experience in data collection. Of note, they all worked at the main maternity (FP and PMTCT) and HIV clinic of YCH. Each interview lasted 45-60 minutes. Approximately three subjects, who were previously informed and had obtained an appointment, were interviewed daily after routine antenatal visit. Similarly, participants were surveyed 2 weeks before delivery to collect data on their attitude on FPS, ART, and pre-exposure prophylaxis (PrEP) access, the delivery option chosen, and the infant nourishment option adopted. Finally, only 94 HIV-infected pregnant women living with HIVnegative partners were included in this study (Figure 1).

\section{Data analysis}

All results were reported as percentages and the chi-squared test $\left(\chi^{2}\right)$ was used for analysis. We performed bivariate analysis to determine the associations between the participants' characteristics (demographic patterns, fertility behavior, and ART use) and the nonuse of contraception. In the general description of contraception, all well-known contraceptive methods were included and then classified into modern and traditional methods. For each potential predictor associated with the "contraception nonuse", we calculated the proportion, and the significant results were reported and described. Analyses were performed to determine women's behavior toward the use of FPS as well as toward prevention of maternal transmission of HIV. All analyses were done with GraphPad Prism ${ }^{\circledR}$ V. 5.01 package (GraphPad Software, Inc., La Jolla, CA, USA), and all statistical analyses were two-sided and considered significant at $P<0.05$.

\section{Ethical considerations}

Measures were taken to ensure confidentiality and anonymity of information provided. This study was approved by the Institutional Review Board of the YCH. Written informed consent was obtained from all subjects prior to their participation in this study.

\section{Results \\ Participants' characteristics}

A total of 94 HIV-infected pregnant women living with HIVnegative partners were enrolled in this study. Participants' mean age was 30.70 years. Results presented in Table 1 show that $69 \%$ of women were in stable couples and the majority (59\%) had completed secondary education. Half of the studied population reported having no stable work, while $63 \%$ of the male partners were working and the large majority were living in urban areas.

\section{Reproductive health and prevention of maternal transmission of HIV}

Results presented in Table 2 summarize the characteristics of reproductive health and maternal transmission of HIV among participants. Only 13\% of the participants reported having received prior conception advice from health care providers. Although almost all the women were knowledgeable about both modern and traditional contraceptives, $19 \%$ of the participants had previously experienced at least one modern contraceptive method, including intrauterine

Table I Demographic characteristics of the study population

\begin{tabular}{lll}
\hline Variables/basic information & Frequency & Percentage \\
\hline Age (mean \pm SD) & $30.70 \pm 5.50$ & \\
$\leq 25$ & 21 & 22 \\
$26-34$ & 47 & 50 \\
$\geq 35$ & 26 & 28 \\
Marital status of the & & \\
participants & & \\
Married/cohabiting & 65 & 69 \\
(stable couples) & & \\
Partnered living separately & 29 & 31 \\
(unstable couples) & & \\
Education level & & \\
Primary and below & 26 & 28 \\
Secondary & 56 & 59 \\
High/university & 12 & 13 \\
Employment status & & \\
Employed & 48 & 51 \\
Unemployed & 46 & 49 \\
Partner's education level & & 32 \\
Primary and below & 30 & 43 \\
Secondary & 40 & 25 \\
High/university & 24 & \\
Partner's employment status & & \\
Employed & 59 & \\
Unemployed & 35 & \\
Residency & & \\
Urban & & \\
Rural & 76 & \\
\hline Abbrevial & & \\
\hline & & \\
\hline
\end{tabular}

Abbreviation: SD, standard deviation. 
Table 2 Characteristics of reproductive health and prevention of maternal transmission of HIV

\begin{tabular}{|c|c|c|}
\hline Variables & $\mathbf{n}$ & $\%$ \\
\hline \multicolumn{3}{|l|}{ Family planning and fertility } \\
\hline $\begin{array}{l}\text { Prior advices on reproductive health from health care } \\
\text { provider in FP unit }\end{array}$ & 12 & 13 \\
\hline $\begin{array}{l}\text { Prior use of modern methods (IUD, DMPA, NET-EN, } \\
\text { implants, pill, ECP, diaphragm) }\end{array}$ & 18 & 19 \\
\hline $\begin{array}{l}\text { Prior use of traditional methods (FABM, withdrawal, } \\
\text { LAM, abstinence, herbs) }\end{array}$ & 28 & 30 \\
\hline Condom use & 62 & 66 \\
\hline Discussion of FP services with male partner & 54 & 57 \\
\hline Have tried to avoid pregnancies (unwanted pregnancies) & 61 & 65 \\
\hline $\begin{array}{l}\text { Abortions/miscarriages and stillbirth in the last } \\
12 \text { months }\end{array}$ & $4 I$ & 44 \\
\hline \multicolumn{3}{|l|}{ Number of living children } \\
\hline 0 & 15 & 16 \\
\hline I & 31 & 33 \\
\hline 2 & 21 & 22 \\
\hline$\geq 3$ & 7 & 7 \\
\hline \multicolumn{3}{|l|}{ Further pregnancies } \\
\hline 0 & 12 & 13 \\
\hline I & 42 & 45 \\
\hline 2 & 18 & 19 \\
\hline$\geq 3$ & 10 & II \\
\hline \multicolumn{3}{|l|}{ HIVIAIDS and maternal transmission } \\
\hline Transmission of HIV from mother to child & 87 & 93 \\
\hline Transmission of HIVIAIDS to uninfected partner & 92 & 98 \\
\hline \multicolumn{3}{|l|}{$\begin{array}{l}\text { Current interventions used to prevent maternal } \\
\text { transmission }\end{array}$} \\
\hline Had disclosed their HIV status to sexual partner & 89 & 95 \\
\hline Are taking ART/ART initiated & 82 & 87 \\
\hline $\begin{array}{l}\text { Respect doctor's prescription of medicine/ART } \\
\text { adherence }\end{array}$ & 64 & 68 \\
\hline $\begin{array}{l}\text { Will take medicine to protect newborn/ART pre- and } \\
\text { postexposure prophylaxis }\end{array}$ & 87 & 93 \\
\hline Plan to avoid breastfeeding & 76 & 81 \\
\hline $\begin{array}{l}\text { Competencies to prevent mother-to-child transmission } \\
\text { of HIV }\end{array}$ & 86 & 92 \\
\hline \multicolumn{3}{|l|}{$\begin{array}{l}\text { Participant self-tasks/inputs for PMTCT } \\
\text { among SDC }\end{array}$} \\
\hline Promote dialogue within couple for FP services use & 77 & 81 \\
\hline Pray and remain in prayer to have a child safe from HIV & $\mathrm{II}$ & 12 \\
\hline Good health conditions and promote hygiene & 7 & 7 \\
\hline \multicolumn{3}{|l|}{ Family planning unmet needs } \\
\hline Modern contraception need & 64 & 68 \\
\hline Education about HIV MTCT & 76 & 81 \\
\hline $\begin{array}{l}\text { Counseling plans for safe conception (safer sex } \\
\text { practices and PMTCT) }\end{array}$ & 55 & 58 \\
\hline Support for ART adherence & 75 & 80 \\
\hline Women rights abuse and violence of male partner & 18 & 19 \\
\hline $\begin{array}{l}\text { Make ART and free-cost checkup really available } \\
\text { every time }\end{array}$ & 32 & 34 \\
\hline
\end{tabular}

Abbreviations: AIDS, acquired immunodeficiency syndrome; ART, antiretroviral therapy; DMPA, depot medroxyprogesterone acetate; ECP, emergency contraceptive pills; FABM, fertility awareness-based methods; FP, family planning; HIV, human immunodeficiency virus; IUD, intrauterine device; LAM, lactational amenorrhea method; MTCT, mother-to-child transmission; NET-EN, norethisterone enanthate; PMTCT, prevention of MTCT; SDC, serodiscordant couples. device $(3 \%)$, implants $(7 \%)$, pills $(28 \%)$, emergency contraception pills (18\%), injection method (7\%) with depot medroxyprogesterone acetate or norethisterone enanthate, and diaphragm (4\%), while about $30 \%$ reported having previously used traditional methods such as withdrawal (32\%), fertility awareness-based methods (45\%), lactational amenorrhea method (18\%), and herbs (4\%). More than half of the participants (68\%) preferred infrequent sex or abstinence. Overall, the majority (66\%) preferred condom use. Although 57\% have discussed FP issues with their partners, about $65 \%$ had tried to avoid the current pregnancy. Importantly, $44 \%$ of the participants reported an event of abortion or miscarriage within the 12 -month period prior to the study. However, $>45 \%$ of the infected women having at least three children expressed the desire to conceive again. The vast majority $(95 \%)$ were aware of the high risk of infection for both their sexual partner and their child. To avoid HIV transmission, a significant proportion of women had disclosed their HIV status or they were planning to avoid breastfeeding the newborn, while $87 \%$ were on ART. However, participants reported several barriers such as the abuse of their rights as women and violence from their male partners (19\%), and $85 \%$ claimed the lack of frequent HIV viral load monitoring or frequent ART shortage (34\%). The lack of modern contraception (68\%), education (81\%), lack of any form of assistance including support from the health care provider and husband were also prevalent.

\section{Predictors of the nonuse of FPS among participants}

Potential predictors associated with the nonuse of FPS are presented in Table 3. Despite the association between education and FPS use, HIV-infected women with no children were less likely to practice any contraception method compared with others having one, two, or three children $(P=0.0001)$. This study revealed that abortions or miscarriages during the previous 12 months were significantly associated with nonuse of FP $(P<0.001)$. Unplanned pregnancies were mostly encountered among women with less FP needs compared to those who reported previous contraception use $(P<0.001)$. We observed the same scenario when assessing interpregnancy spacing and nonuse of FP. Women who wanted to delay the pregnancy after their marriage and those who wanted the child 2 years later were more likely to opt for FPS, contrary to those wishing to have the next child in the nearest future $(P<0.001)$. Despite having discussed with their sexual partner, their opinions were also associated with decision making to avoid the use of 
Table 3 Predictive factors influencing contraception nonuse among HIV (+) women

\begin{tabular}{|c|c|c|c|c|}
\hline \multirow[t]{2}{*}{ Variables } & \multirow[t]{2}{*}{ Category } & \multicolumn{2}{|c|}{ Contraception nonuse } & \multirow[t]{2}{*}{$P$-value } \\
\hline & & Yes (\%) & No (\%) & \\
\hline \multirow[t]{4}{*}{ Education level } & & & & $0.009 *$ \\
\hline & Primary & $24(63.2)$ & $14(37)$ & \\
\hline & Secondary & 31 (68.9) & $14(31)$ & \\
\hline & High & $9(82)$ & $2(18)$ & \\
\hline \multirow[t]{5}{*}{ Number of living children } & & & & $0.0001 * *$ \\
\hline & 0 & $15(100)$ & $(0)$ & \\
\hline & 1 & $31(91)$ & $3(9)$ & \\
\hline & 2 & $21(70)$ & $9(30)$ & \\
\hline & $\geq 3$ & $7(58)^{\prime}$ & $5(42)$ & \\
\hline \multirow{4}{*}{$\begin{array}{l}\text { Abortions/miscarriage during the } \\
\text { last } 12 \text { months }\end{array}$} & & & & $0.0001 * *$ \\
\hline & & & & \\
\hline & Yes & $26(46)$ & $31(54)$ & \\
\hline & No & $37(76)$ & $12(24)$ & \\
\hline \multirow[t]{5}{*}{ Number of future children } & & & & 0.0655 \\
\hline & 0 & $12(80)$ & $3(20)$ & \\
\hline & I & $42(91)$ & $4(7)$ & \\
\hline & 2 & $18(86)$ & $3(14)$ & \\
\hline & $\geq 3$ & $10(83)$ & $2(17)$ & \\
\hline \multirow[t]{3}{*}{ Unplanned pregnancies } & & & & $0.000 \mathrm{I} * *$ \\
\hline & Yes & $5(8)$ & $56(92)$ & \\
\hline & No & $30(91)$ & $3(9)$ & \\
\hline \multirow[t]{6}{*}{ Interpregnancy spacing } & & & & $0.000 \mathrm{I} * *$ \\
\hline & As soon as possible & $3(30)$ & $7(70)$ & \\
\hline & After marriage & $8(100)$ & $0(00)$ & \\
\hline & $\mathrm{I}-2$ years & $17(94)$ & I (6) & \\
\hline & $>2$ years & $25(100)$ & $0(00)$ & \\
\hline & Don't know & $29(88)$ & $4(12)$ & \\
\hline \multirow{5}{*}{$\begin{array}{l}\text { Partner's decision to operate } \\
\text { for FP }\end{array}$} & & & & $0.000 \mathrm{I} * *$ \\
\hline & & & & \\
\hline & Yes & $39(80)$ & $10(20)$ & \\
\hline & No & $25(100)$ & $0(00)$ & \\
\hline & Don't know & $18(90)$ & $2(10)$ & \\
\hline \multirow[t]{4}{*}{ ART adherence } & & & & $0.000 \mathrm{I} * *$ \\
\hline & $\leq 25$ & $17(81)$ & $4(19)$ & \\
\hline & $26-34$ & $36(77)$ & II (23) & \\
\hline & $\geq 35$ & II (42) & $15(58)$ & \\
\hline \multirow[t]{5}{*}{ ART accessibility for PMTCT } & & & & $0.0001 * *$ \\
\hline & Every time & $26(96)$ & I (4) & \\
\hline & Sometime & $51(98)$ & $I(2)$ & \\
\hline & Hardly & $2(67)$ & I (33) & \\
\hline & Never have been on ART & $3(25)$ & $9(75)$ & \\
\hline
\end{tabular}

Notes: $* P<0.05 ; * * P<0.001$. Statistically significant values are shown in bold.

Abbreviations: ART, antiretroviral therapy; FP, family planning; HIV, human immunodeficiency virus; PMTCT, prevention of mother-to-child transmission of HIV.

contraception $(P<0.001)$. When analyzing ART adherence and accessibility, women above 35 years of age were more adhering and faithful vis-à-vis FP than others. Furthermore, the lack of ART procurement significantly affected the nonuse of contraceptive methods $(P<0.001)$.

\section{Effect of counseling on HIV-infected women's behavior toward PMTCT}

After an average of about 6 months following counseling and education on HIV/AIDS education, use of FPS, ART therapy, PrEP, delivery method, and infant feeding option for PMTCT, women's awareness had increased (Figure 2). Use of FPS and ART compliance increased from $25 \%$ and $76 \%$ to $82 \%$ and $96 \%$, respectively. Similarly, women's awareness on PrEP and newborn feeding measures also increased from $7 \%$ and $40 \%$ to $48 \%$ and $80 \%$, respectively $(P<0.001)$.

Pregnant women's preferred strategies for PMTCT: delivery method and infant nourishment option after counseling

The difference observed on the choice of delivery method as well as the infant nourishment options after counseling highlighted the fact that about $77 \%$ of the HIV-infected pregnant women still wanted to procreate naturally, while $28 \%$ opted 


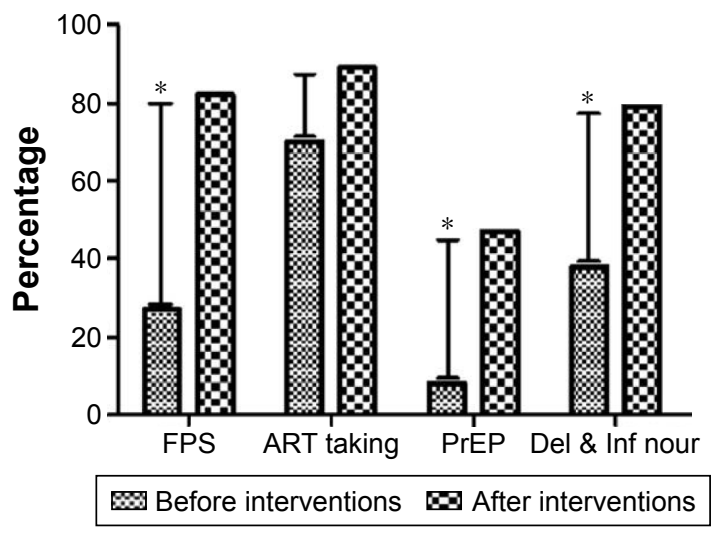

Figure 2 Effects of counseling for PMTCT of HIV-infected women. Notes: $* P<0.001$. Error bars compared the differences in term of FPS use, ART adherence, PrEP knowledge, and Del \& Inf nour options before and after interventions among participants.

Abbreviations: ART, antiretroviral therapy; Del \& Inf nour, delivery and infant nourishment; FPS, family planning services; HIV, human immunodeficiency virus: PMTCT, prevention of mother-to-child transmission; PrEP, pre-exposure prophylaxis.

for elective cesarean, $40 \%$ chose exclusive breastfeeding, and $60 \%$ preferred infant formulation food (Figure 3 ).

\section{Contributing framework and implications in practice}

The framework presented in Figure 4 has been derived from this study. In short, this framework consists of six marked steps incorporating both discordant reproductive health characteristics and major factors requiring more consideration to reduce new infections in resource-limited settings. The framework incorporates the critical factors and their mechanisms influencing both the fertility intentions and use of FPS among HIV-discordant couples to prevent both heterosexual and mother-to-child transmission.

\section{Discussion}

FP is a voluntary and informed decision by an individual or a couple on their fertility intention. It takes into account the number of children to have and when to have them. It can also be simply referred to as having children by choice and not by chance.

Despite the fact that all our subjects were partnered with an HIV-negative individual and 69\% were engaged in a stable relationship, use of FPS was lower among members of this study population compared to the general population in Cameroon. ${ }^{25,27}$ These findings are in agreement with those reported by previous studies. ${ }^{33-35}$ Although the majority of participants mainly preferred traditional contraception and condom use, condom use alone is not sufficient to avoid or delay pregnancy. In contrast with a recent study conducted in Malawi, ${ }^{36}$ many other investigations have demonstrated that HIV-infected individuals were less likely to use condoms, especially when they are capable of bearing a child. ${ }^{11,14,29,37}$ We found that condoms were inconsistently and incorrectly used for FP issues and to prevent HIV transmission to uninfected partners. Moreover, the large majority of participants preferred infrequent sex and coitus interruptus practices. Consequently, the main predictors of nonuse of FPS (number of living children, abortion/miscarriages, unwanted pregnancies, inconsistent pregnancy spacing, partners' decision, ART access and adherence) were significant, indicating the failure of use of contraception in this area. These are, therefore, the critical factors characterizing HIV-positive women's behavior regarding the nonuse of FPS. Though stable couples were predominant in this study, we noticed that a significant proportion of women

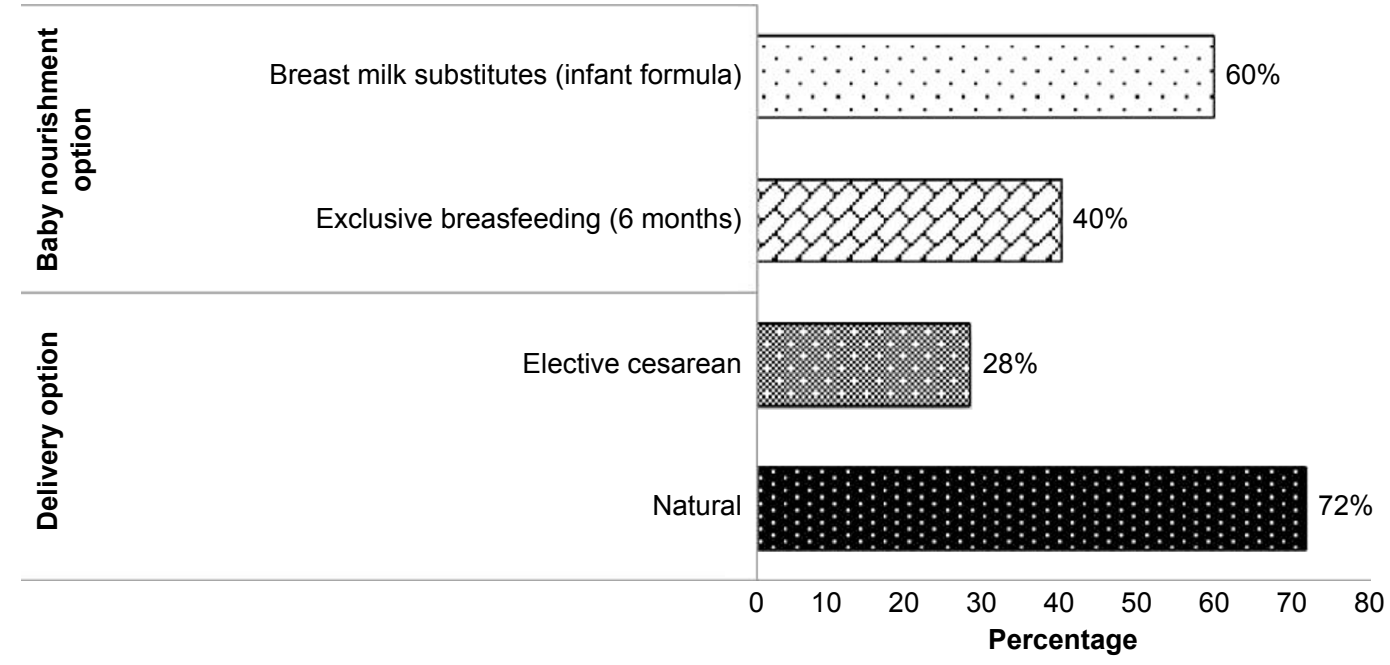

Figure 3 Pregnant women's choice trends for preventing mother-to-child transmission of HIV: delivery method and infant nourishment option after counseling. Abbreviation: HIV, human immunodeficiency virus. 


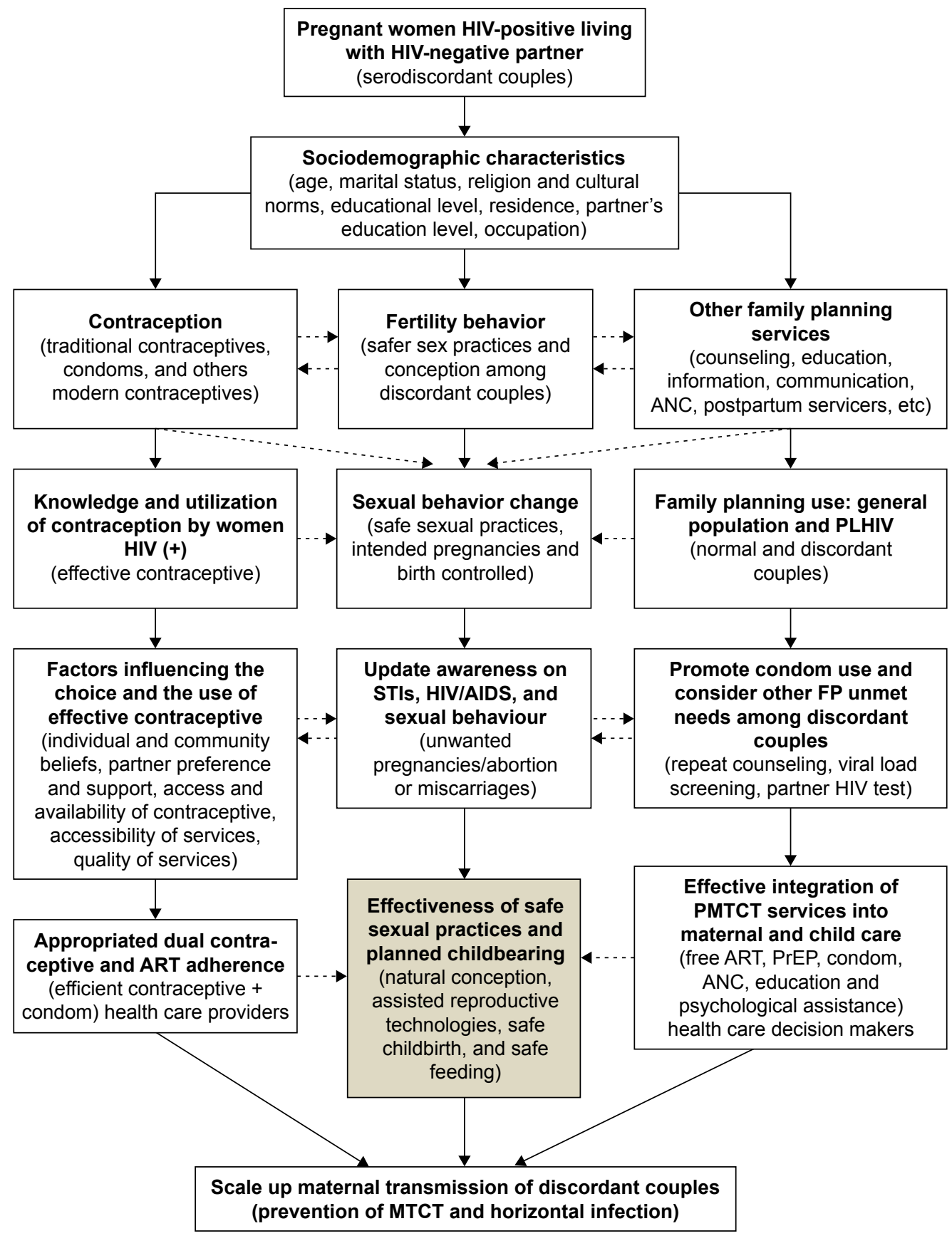

Figure 4 Framework for improving the prevention of maternal transmission of HIV in resource-limited settings.

Abbreviations: AIDS, acquired immunodeficiency syndrome; ANC, antenatal care; ART, antiretroviral therapy; FP, family planning; HIV, human immunodeficiency virus; MTCT, mother-to-child transmission; PLHIV, people living with HIV; PMTCT, prevention of mother-to-child transmission; PrEP, pre-exposure prophylaxis; STIs, sexually transmitted infections.

were in unstable relationships. Recently, Chemaitelly et al demonstrated that the spread of HIV among discordant couples in SSA is associated with marital status. ${ }^{9} 12$ However, the infection of the HIV-negative partner, especially men, can reach an average of $29.4 \%$ and $40.2 \%$ among stable and unstable discordant couples, respectively. ${ }^{11,30}$ Therefore, our results highlighted the urgent need to promote stable and faithful relationships among discordant couples when any opportunity is offered. Although women were knowledgeable about effective contraceptive methods, they did not apply them to delay or control their fertility. It can, therefore, be speculated that barriers including the misconception of FPS, lack of education and ignorance, partners' opposition, and the accessibility and availability of effective contraceptive methods may play a key role in the use of contraception among HIV-infected individuals. These limitations of 
both education and actions to prevent HIV transmission may worsen the state of reproductive health in Cameroon. Minimal use of contraception and high unmet needs for FPS are the major causes of unintended pregnancies and shorter pregnancy intervals in developing countries. ${ }^{31,34,37}$ Innovative approaches that should consider these barriers and men's opinion are needed to arouse women's interest and change their current behavior in the utilization of least effective contraception methods.

Though many recommendations and studies have suggested the integration of PMTCT and, especially, ART provision in FPS, 5, 15,34,38 our findings revealed that HIV pregnant women were constantly having the fear of transmitting the virus to their children. Almost all the women reported doing everything possible to protect their infants from HIV. This is the first time that a study has attempted to describe HIV-infected pregnant women's feeling toward their unborn babies. Though this connection may dramatically increase during the pregnancy period, ART therapy and adherence are undeniably effective to reduce heterosexual and vertical transmission. ${ }^{16,24,38,39}$ A great proportion of women reported the lack of psychological support and their household violence, which may significantly affect the biological function to reinforce their immune system. Despite the other recurrent unmet needs reported by the participants (ART shortage, absence of HIV viral load monitoring, lack of dialogue within couples, women rights abuse), we argue that the environment and related factors may limit the protective function of highly active antiretroviral therapy (HAART) in resource-limited settings. Therefore, it is likely that all these barriers converge to increase the risk of both horizontal and vertical transmission among discordant partners. In accordance with Haddad et al, we recommend that additional new approaches should be incorporated into ART provision in the era of elimination of MTCT. ${ }^{36}$ In Cameroon, once a pregnant woman is detected HIV positive, she must be referred to HIV care specialists before ART initiation. Also, HAART is not available in all community health centers other than the official treatment centers (Unité de Prise En Charge and Centre de Traitement Agréé). We, therefore, recommend the revision of existing health policies to incorporate direct follow-up of pregnant women infected with HIV in the community health centers providing reproductive care.

At baseline, women's knowledge was lower with inadequate awareness of PMTCT. Most of the "self-tasks and inputs for PMTCT" reported by women, such as prayer, hygiene, promoting good health conditions, or dialogue with partner, are not enough to stop heterosexual and vertical infection. In addition, participants' knowledge had significantly increased 6 months after the counseling and education sessions focused on use of FPS, ART therapy and adherence, PrEP, delivery methods, and infant feeding. The positive impact of counseling and educational sessions approach used was quite noticeable and remarkable through women's behavior during the decision making for opting natural or cesarean method, exclusive breastfeeding or using breast milk substitute during delivery, and baby nourishment These factors account for a large part of new HIV infections among children. Therefore, regular counseling, education, and communication are crucial among the efforts to promote medical care and ensure HIV-infected persons' adherence to treatment. Similar to the situation in most developing countries, ${ }^{12,16,29,40}$ a large proportion of HIV-infected pregnant women in this setting may not be able to afford the more effective means such as continuous ART procurement, elective cesarean, and using infant milk substitute, because of limited financial resources.

Although many HIV-infected women still do not have sufficient medical care and family support to stop new infections in resource-limited settings, the conceptual framework derived from the findings of this study suggests several promising points of interventions to improve FPS and consequently curb HIV infection. Overall, the framework sets and fits the interactions between factors that were assessed in the current study. However, its implementation and assessment are warranted.

\section{Limitations}

There were some limitations in this survey. This study was of cross-sectional design with a small sample size. Only HIV-infected women engaged with HIV-negative partners were surveyed, relying the participants' memory for many variables. Biomedical parameters such as time on ART, CD4 count, and viral load plasma, which are crucial in PMTCT, were not assessed during this study. Moreover, participants were a highly selected population because of pregnancy, and therefore, they were unlikely to be representative as all HIVinfected women across the country. Therefore, randomized trial studies including all these factors across the country are warranted and caution should be exercised in generalizing our findings.

\section{Conclusion}

Although the vast majority of HIV-infected women are knowledgeable about effective contraceptive methods, they still use condoms inconsistently together with other 
ineffective contraceptive methods, with the consequence being numerous pregnancies, abortions, and miscarriages. Several barriers including the misconception of FPS, lack of education, partners' opinion, and social living conditions limit the utilization of effective contraception among HIV-discordant couples. Similarly, single use of ART is highly limited to prevent new infections. The framework provided in this study gives sufficient evidence to rethink vertical and horizontal transmission of HIV in Cameroon. The scale-up of FPS by incorporating routine PMTCT activities into reproductive health care is an excellent opportunity to prevent both heterosexual and mother-to-child transmission in resource-limited settings.

\section{Acknowledgments}

This study was supported by the Awards from Anhui Biochem United Pharmaceutical Company of People's Republic of China and the Family Planning and Reproductive Institute of Tongji Medical College. The authors gratefully acknowledge the clinical staff and participants from Yaounde Central Hospital for their contributions.

\section{Author contributions}

All authors made substantial contributions to conception and design, acquisition of data, or analysis and interpretation of data; took part in drafting the article or revising it critically for important intellectual content; gave final approval of the version to be published; and agree to be accountable for all aspects of the work.

\section{Disclosure}

The authors report no conflicts of interest in this work.

\section{References}

1. United Nations. The millennium development goals. 2000; Available from: http://www.un.org/en/events/pastevents/millennium_summit. shtml. Accessed June 20, 2015.

2. UNFPA. Countdown of the last 1,000 days to achieve the millennium development goals in 2015; 2015. Available from: http://www.unfpa. org/news/countdown-last-1000-days-achieve-millennium-developmentgoals-2015. Accessed July 26, 2015.

3. Joint United Nations Programme on HIV/AIDS. Global AIDS Response Progress Reporting 2015; 2015. Available from: http://www.unaids.org/ sites/default/files/media_asset/JC2702_GARPR2015guidelines_en.pdf. Accessed June 27, 2015.

4. Joint United Nations Programme on HIV/AIDS. Global Report: UNAIDS Report on the Global AIDS Epidemic 2013; 2013. Available from: http://www.unaids.org/en/media/unaids/contentassets/documents/ epidemiology/2013/gr2013/UNAIDS_Global_Report_2013_en.pdf. Accessed July 10, 2015.

5. Joint United Nations Programme on HIV/AIDS. 2011-2015 Strategy: Getting to Zero. 2010; 2010. Available from: http://www.unaids.org/ sites/default/files/sub_landing/files/JC2034_UNAIDS_Strategy_en.pdf. Accessed June 30, 2015.
6. Joint United Nations Programme on HIV/AIDS. Global AIDS Response Progress Reporting 2014: Construction of Core Indicators for Monitoring the 2011 United Nations Political Declaration on HIV and AIDS; 2014. Available from: http://www.unaids.org/sites/default/files/ media_asset/GARPR_2014_guidelines_en_0.pdf. Accessed June 10, 2015.

7. Breitnauer BT, Mmeje O, Njoroge B, Darbes LA, Leddy A, Brown J. Community perceptions of childbearing and use of safer conception strategies among HIV-discordant couples in Kisumu, Kenya. $J$ Int AIDS Soc. 2015;18:19972.

8. Muldoon KA, Duff PK, Birungi J, et al. Decisions, decisions: the importance of condom use decision making among HIV sero-discordant couples in a prospective cohort study in Uganda. Sex Transm Infect. 2014;90(5):408-412.

9. Chemaitelly H, Awad SF, Abu-Raddad LJ. The risk of HIV transmission within HIV-1 sero-discordant couples appears to vary across subSaharan Africa. Epidemics. 2014;6:1-9.

10. Bobashev G, Norton J, Wechsberg W, Toussova O. Are you HIV invincible? A probabilistic study of discordant couples in the context of HIV transmission. PLoS One. 2014;9(5):e94799.

11. Eyawo O, de Walque D, Ford N, Gakii G, Lester RT, Mills EJ. HIV status in discordant couples in sub-Saharan Africa: a systematic review and meta-analysis. Lancet Infect Dis. 2010;10(11):770-777.

12. Chemaitelly H, Awad SF, Shelton JD, Abu-Raddad LJ. Sources of HIV incidence among stable couples in sub-Saharan Africa. J Int AIDS Soc. 2014; 17:18765.

13. Chemaitelly H, Cremin I, Shelton J, Hallett TB, Abu-Raddad LJ. Distinct HIV discordancy patterns by epidemic size in stable sexual partnerships in sub-Saharan Africa. Sex Transm Infect. 2012;88(1):51-57.

14. Guthrie BL, de Bruyn G, Farquhar C. HIV-1-discordant couples in sub-Saharan Africa: explanations and implications for high rates of discordancy. Curr HIV Res. 2007;5(4):416-429.

15. WHO. PMTCT Strategic Vision 2010-2015: Preventing Mother-toChild Transmission of HIV to Reach the UNGASS and Millennium Development Goals. Geneva: WHO; 2010. Available from: http://www. who.int/hiv/pub/mtct/strategic_vision.pdf?ua=1. Accessed July 20, 2015.

16. Hallett TB, Baeten JM, Heffron R, et al. Optimal uses of antiretrovirals for prevention in HIV-1 serodiscordant heterosexual couples in South Africa: a modelling study. PLoS Med. 2011;8(11):e1001123.

17. Kimani J, Warren CE, Abuya T, et al. Use of HIV counseling and testing and family planning services among postpartum women in Kenya: a multicentre, non-randomised trial. BMC Womens Health. 2015; $15: 104$

18. Sarnquist CC, Rahangdale L, Maldonado Y. Reproductive health and family planning needs among HIV-infected women in sub-Saharan Africa. Curr HIV Res. 2013;11(2):160-168.

19. Msellati P. Improving mothers' access to PMTCT programs in West Africa: a public health perspective. Soc Sci Med. 2009;69(6): 807-812.

20. Warren CE, Abuya T, Askew I, Initiative I. Family planning practices and pregnancy intentions among HIV-positive and HIV-negative postpartum women in Swaziland: a cross sectional survey. BMC Pregnancy Childbirth. 2013;13:150.

21. Onono M, Guze MA, Grossman D, et al. Integrating family planning and HIV services in western Kenya: the impact on HIV-infected patients' knowledge of family planning and male attitudes toward family planning. AIDS Care. 2015;27(6):743-752.

22. Shade SB, Kevany S, Onono M, et al. Cost, cost-efficiency and costeffectiveness of integrated family planning and HIV services. AIDS. 2013;27 (Suppl 1):S87-S92.

23. Haider TL, Sharma M. Barriers to family planning and contraception uptake in sub-Saharan Africa: a systematic review. Int $Q$ Community Health Educ. 2012;33(4):403-413.

24. Gourlay A, Birdthistle I, Mburu G, Iorpenda K, Wringe A. Barriers and facilitating factors to the uptake of antiretroviral drugs for prevention of mother-to-child transmission of HIV in sub-Saharan Africa: a systematic review. J Int AIDS Soc. 2013;16:18588. 
25. UNAIDS. Rapport national de suivi de la declaration politique sur le VIH/SIDA Cameroon: Global Aids Response Progress (GARP). 2014; Available from: http://www.unaids.org/sites/default/files/country/documents/CMR_narrative_report_2014.pdf. Accessed August 14, 2015.

26. Billong SC, Fokam J, Billong EJ, et al. Distribution épidémiologique de l'infection à VIH chez les femmes enceintes dans les dix régions $\mathrm{du}$ Cameroun et implications stratégiques pour les programmes de prévention. Pan Afr Med J. 2015;20(79):1-9.

27. Institut National de la Statistique et ICF International. Republique du Cameroon: Enquete demographique et de sante et a indicateurs multiples 2011 [Republic of Cameroon: demographic and health survey and multiple indicators cluster survey 2011]; 2012. Available from: http:// dhsprogram.com/pubs/pdf/FR260/FR260.pdf. Accessed August 12, 2015. French.

28. Commonwealth Foundation. A Civil Society Review of Progress Towards the Millennium Development Goals in Commonwealth countries. National Report: Cameroon; 2013. Available from: http://www commonwealthfoundation.com/sites/cwf/files/downloads/MDG\%20 Reports\%20Cameroon_FINAL_1.pdf. Accessed June 10, 2015.

29. Schwartz SR, Mehta SH, Taha TE, Rees HV, Venter F, Black V. High pregnancy intentions and missed opportunities for patient-provider communication about fertility in a South African cohort of HIV-positive women on antiretroviral therapy. AIDS Behav. 2012;16(1):69-78.

30. Golin CE, Davis RA, Przybyla SM, et al. Safetalk, a multicomponent, motivational interviewing-based, safer sex counseling program for people living with HIV/AIDS: a qualitative assessment of patients' views. AIDS Patient Care STDS. 2010;24(4):237-245.

31. Cleland J, Bernstein S, Ezeh A, Faundes A, Glasier A, Innis J. Family planning: the unfinished agenda. Lancet. 2006;368(9549): 1810-1827.

32. WHO and CDC. Effectiveness of Family Planning Methods. CDC and WHO; 2011. Available from: http://www.cdc.gov/reproductivehealth/ UnintendedPregnancy/PDF/Contraceptive_methods_508.pdf. Accessed March 20, 2014.
33. Duncan S, Hawkins F, Desmond N. Postnatal contraceptive choices among women living with HIV: decade of experience in a communitybased integrated sexual health clinic. J Fam Plan Reprod Health Care. 2013;39(1):17-20.

34. Akelo V, Girde S, Borkowf CB, et al. Attitudes toward family planning among HIV-positive pregnant women enrolled in a prevention of mother-to-child transmission study in Kisumu, Kenya. PLoS One. 2013;8(8):e66593.

35. King R, Katuntu D, Lifshay J, et al. Processes and outcomes of HIV serostatus disclosure to sexual partners among people living with HIV in Uganda. AIDS Behav. 2008;12(2):232-243.

36. Haddad LB, Feldacker C, Jamieson DJ, et al. Pregnancy prevention and condom use practices among HIV-infected women on antiretroviral therapy seeking family planning in Lilongwe, Malawi. PLoS One. 2015; 10(3):e0121039.

37. Finger JL, Clum GA, Trent ME, Ellen JM, HIV AMTN. Desire for pregnancy and risk behavior in young HIV-positive women. AIDS Patient Care St. 2012;26(3):173-180.

38. Matthews LT, Smit JA, Cu-Uvin S, Cohan D. Antiretrovirals and safer conception for HIV-serodiscordant couples. Curr Opin HIV AIDS. 2012;7(6):569-578.

39. Tanser F, Barnighausen T, Grapsa E, Zaidi J, Newell ML. High coverage of ART associated with decline in risk of HIV acquisition in rural KwaZulu-Natal, South Africa. Science. 2013;339(6122):966-971.

40. Cohen MS, Chen YQ, McCauley M, et al. Prevention of HIV-1 infection with early antiretroviral therapy. $N$ Engl J Med. 2011;365(6): 493-505.
Patient Preference and Adherence

\section{Publish your work in this journal}

Patient Preference and Adherence is an international, peer-reviewed, open access journal that focuses on the growing importance of patient preference and adherence throughout the therapeutic continuum. Patient satisfaction, acceptability, quality of life, compliance, persistence and their role in developing new therapeutic modalities and compounds to optimize

\section{Dovepress}

clinical outcomes for existing disease states are major areas of interest for the journal. This journal has been accepted for indexing on PubMed Central. The manuscript management system is completely online and includes a very quick and fair peer-review system, which is all easy to use. Visit http://www. dovepress.com/testimonials.php to read real quotes from published authors. 